\title{
Effective EU and Member State policies for stimulating CCS
}

\author{
Heleen Groenenberg *, Heleen de Coninck \\ ECN Policy Studies, P.O. Box 56890, 1040 AW Amsterdam, The Netherlands
}

\section{A R T I C L E I N F O}

Article history:

Received 19 October 2007

Received in revised form

25 March 2008

Accepted 4 April 2008

Published on line 2 June 2008

Keywords:

$\mathrm{CO}_{2}$ capture and storage (CCS)

Innovation

Emissions trading (ETS)

Subsidies

Feed-in tariffs

Low-carbon portfolio

Market-based instruments

Regulation

Multi-criteria analysis

Public acceptance

\begin{abstract}
A B S T R A C T
Although $\mathrm{CO}_{2}$ capture and storage (CCS) is widely recognised as an option to mitigate climate change, consistent and effective EU policies to advance CCS are still absent. This paper discusses policy instruments for advancing large-scale deployment of CCS in the European Union, and evaluates them in a multi-criteria analysis. The EU Emissions Trading Scheme (EU-ETS) is a cost-effective instrument for limiting greenhouse gas emissions, but it is questionable whether its currently limited time horizon and short-trading periods will lead to substantial CCS diffusion. Complementary policies at the EU and the Member State level may repair this and provide sufficient incentives for CCS. Potential policies include financial instruments such as investment subsidies, a feed-in scheme, or a $\mathrm{CO}_{2}$ price guarantee, as well as a CCS mandate or a low-carbon portfolio. These policy options differ with respect to their environmental effectiveness, possible interaction with the EU-ETS, costs and financial risk involved, and their competition with other mitigation options. Interactions between Member State policies and the EU-ETS are smaller in scope than those of EU-wide policies, but they are more likely to lead to displacement of financial resources from other low-carbon technologies. In addition, national policies may pose a significant part of the financial risk of CCS operations with Member States, reducing the operator's incentive to innovate. Overall, structural policies at the EU level, such as a mandate or a lowcarbon portfolio standard would be more conducive for realising large-scale deployment of CCS across the EU as well as more acceptable to environmental organisations.
\end{abstract}

(C) 2008 Elsevier Ltd. All rights reserved.

\section{Introduction}

$\mathrm{CO}_{2}$ capture and storage (CCS) is currently not deployed on a commercial scale. Yet, within Europe, CCS is considered crucial for achieving the EU's ambitious targets of reducing greenhouse gas emissions by $20 \%$ or even $30 \%$ below 1990 levels (EC, 2007). Principal barriers to further CCS technologies so far include the lack of a legal framework to regulate the risks related to $\mathrm{CO}_{2}$ storage, and the high costs of many CCS operations (see, e.g., IPCC, 2005). An enabling legal framework that regulates the risks of geological storage of $\mathrm{CO}_{2}$ was recently released by the European Commission (EC, 2008a). In the same package, the Commission proposes to bring CCS into its Emissions Trading Scheme (ETS), thus providing an incentive for deploying CCS. However, a large gap exists between the carbon avoidance costs of CCS, which shows a range of $20-60 € / \mathrm{tCO}_{2}$, and the carbon price, varying between 6 and $30 € / \mathrm{tCO}_{2}$ (PointCarbon, 2007). This gap, in combination with the volatility of the carbon price, render it likely that additional incentivising policies will be needed to ensure large-scale deployment of CCS.

The 2007 Spring Council endorsed the Commission's intention to realise up to 12 demonstrations of clean fossil fuel technologies by 2015 (European Council, 2007), suggested earlier by the ZEP Technology Platform (ZEP, 2006). Further upscaling of the option is foreseen for the years beyond 2015. However, the European Commission has argued that with the review of the EU-ETS it has created the right market

\footnotetext{
* Corresponding author. Tel.: +31 224564516.

E-mail address: groenenberg@ecn.nl (H. Groenenberg). 1750-5836/\$ - see front matter (C) 2008 Elsevier Ltd. All rights reserved. doi:10.1016/j.ijggc.2008.04.003
} 
incentives. Further efforts to realise the CCS demonstrations will need to be undertaken by industry and the Member States (EC, 2008b). This renders the question of adequate policies even more important.

This article aims to address the question what policy options are available at the EU and the Member State level to advance CCS, and what policy is preferable in view of the large cost barrier the technology still faces. To that end it is necessary to look into the impact environmental policies may have on technological innovation in general. Many economists favour the EU Emissions Trading Scheme (EU-ETS) as a principal instrument to advance cleaner technologies. The article will therefore assess to what extent the EU-ETS may be capable to stimulate large-scale diffusion of CCS technologies, and whether complementary policies will be necessary. Next, it will provide a discussion of the merits and limitations of such complementary policies. The article will not go into other, noneconomic, barriers to CCS, such as public acceptance and risks [see for a detailed discussion (DNV, 2007; de Coninck et al., 2007)], nor will it deal with ways to realise a $\mathrm{CO}_{2}$ transport infrastructure in the EU (see e.g., Hendriks et al., 2003), for instance by public-private partnerships. Although we are aware of the importance of the transport question, we will focus the discussion in this paper on the means to facilitate CCS as a whole.

This article sets out with a generic discussion on the impacts of environmental policies on technological innovation (Section 2). Next, it will detail the policy options for giving incentives to CCS through market-based or regulatory instruments, at the Member State and at the EU level (Section 3). It will explore the identified incentivising policy options and their interaction with the ETS, evaluate cost implications, as well as competition with renewable energy for public funds (Section 4). It will then provide a multi-criteria analysis for the various policy options in accordance with the European Commission Guidelines for Impact Assessments (Section 5). Finally, we will evaluate timing of policies to provide an effective incentive to large-scale CCS deployment (Section 6), and close with some general conclusions and recommendations (Section 7).

\section{The impact of policy on technological innovation}

\subsection{Ingredients for a transition to a low-carbon energy system}

It has been argued that the challenge for climate policies is to stimulate emission reductions that go beyond optimisation of the present energy system, and to make the transition towards new systems (OECD, 2003). While cost-effective short-term actions are necessary without doubt, policies focusing on technology innovation and development in the longer term are a prerequisite to eventually realise a low-carbon society. $\mathrm{CO}_{2}$ capture and storage may well play a pivotal role in the transition to such a society, since it may help bring about major reductions while other low or zero-emission technologies are being developed further. Although there is relatively little insight in the nature and design of long-term transition processes, many authors (e.g., Kemp, 2000; Geels et al., 2004;
Suurs and Hekkert, 2005; van den Bergh et al., 2007; Sartorius and Zundel, 2005) have reflected on fundamental ingredients of long-term strategies for technological innovation. A longterm horizon for energy policies is needed to provide companies and consumers with the confidence that investments in climate-friendly technologies will eventually pay off (Kemp, 2000; Geels et al., 2004; Sartorius and Zundel, 2005). Furthermore, a varied knowledge base and support for a diverse portfolio of innovative and promising technologies is crucial to an effective strategy for a long-term energy transition (Kemp, 2000; Geels et al., 2004). Nevertheless, they acknowledged that it is important to seek short-term efficiencies in the present energy system, and to take advantage of the numerous nearly commercial and costeffective reduction options available. These elements of an effective innovation strategy are discussed below.

\subsection{Cost-effective emission reductions in the present energy system}

While a long-term horizon is required to eventually realise the transition to a new energy system, this should not rule out opportunities for reducing emissions and improving supply security in the present energy system in a cost-effective way. Price instruments are considered necessary to achieve shortterm emission reductions with the current set of demonstrated and nearly commercial energy technologies. Such instruments may well lead to further diffusion of economically attractive technologies that are close to commercialisation.

Economists generally believe that market-based instruments can provide stronger incentives than command-andcontrol regulations to adopt cheaper and better technologies. While modelling studies and theoretical arguments abound, empirical evidence for this conjecture is scarce, for various reasons (Vollebergh, 2007): (1) the use of market-based instruments to date has been limited, (2) the same environmental issue is often tackled with a mix of instruments at the same time, (3) different instruments are seldom compared by using them in similar circumstances, and (4) studies that compare instruments in environments where economic conditions are controlled are almost non-existent. Vollebergh (2007) published an extensive review on the differential impact of environmental instruments on technological change, in which he summarised the available empirical literature. He concluded that environmental policy in general has an impact on at least the direction of technological change, and that this conclusion holds for both environmental regulations and market-based instruments.

The EU-ETS was introduced as a market-based approach to reduce $\mathrm{CO}_{2}$ emissions in a cost-effective manner. In its present from, the scheme may well advance the introduction of cleaner technologies that have been demonstrated and are well on their way towards commercialisation. In order to do so, the scheme should solve two market failures: the externality of environmental impacts, and the lack of incentives for technological change (Jaffe and Stavins, 1994; Sutherland, 2000; Jaffe et al., 2005). The common market failure of not internalising environmental damage in production costs is addressed to a certain degree by the ETS, since it gives a price to the environmental externality of $\mathrm{CO}_{2}$ emissions. 
The second market failure, often called the innovation market failure, is not solved by cap-and-trade approaches, as they do not fully provide the incentives needed to compensate innovators for inducing technological change (e.g., Sorrell and Sijm, 2003). The return on investment for innovation towards step-change technologies that involve particularly high innovation costs (such as CCS) is unlikely to be sufficient, even at relatively high carbon prices.

What also does not help is that investment decisions are taken with a longer time horizon in mind than the short-term horizon of the trading periods in the EU-ETS so far. The amendments to the ETS Directive proposed by the European Commission (EC, 2008c) envision a longer crediting period, which will most likely advance the introduction of relatively new technologies. Yet, operators of installations are still likely to prefer the technological options that are more competitive and cost-effective in the short term, as long-term benefits are uncertain.

In brief, while the prospects for sufficiently deep cost reductions for CCS in the short term are dim, and while a host of more cost-effective abatement options are available in installations included in the EU-ETS, we will in this article assume that it is unlikely that CCS will be significantly incentivised through the EU-ETS.

\subsection{Long-term transition of the energy system}

Promoting technological innovation beyond the present energy system however will require efforts beyond the optimisation of the present energy system. It implies not only the introduction of better technologies in isolation, but rather a fundamental change to the entire energy system (OECD, 2003). Such a fundamental change includes a revision of energy supply routes and infrastructures for e.g., electricity, hydrogen, or $\mathrm{CO}_{2}$, and will require concerted actions by stakeholders in both industries and governments. As argued earlier, CCS may well play an important role in this transition.

A varied knowledge base and policies tailored to the barriers distinct technologies face are a prerequisite to eventually bring about an energy transition. It is widely recognised in policy literature (Zundel et al., 2005; Sandén and Azar, 2005) that the maturity of a technology should be part of the decision on both the type and timing of policy, in order to provide maximal leverage of the undertaken policy actions. The various components of the CCS technological value chain are still in different categories of technological maturity (IPCC, 2005). Enhanced coal-bed methane recovery, for instance, is thought to be in the demonstration phase, whereas another storage option, enhanced oil recovery (EOR), is characterised as a mature market technology. Oxyfuel combustion is in the research phase, while pre- and post-combustion capture of $\mathrm{CO}_{2}$ are "economically feasible under specific conditions". ${ }^{1}$ High-investment costs are a major barrier to full-chain CCS

\footnotetext{
1 "Economically feasible under specific conditions" (IPCC, 2005) means that the technology is well understood and is applied in selected commercial applications, but only if the market conditions are conducive to the technology, such as in a favourable tax regime or a niche market. It is sometimes called "supported commercial" as well (Watson et al., 2007).
}

demonstrations (IPCC, 2005). As the technology matures further, policies may focus on further reduction of technological and financial risks.

In view of the innovation failure of the EU-ETS discussed above, a range of complementary policy instruments may be considered at the EU and Member State level to provide adequate incentives for CCS. Regulation at the EU level is an obvious option to compel industry to capture and store its $\mathrm{CO}_{2}$, providing an EU-wide level-playing field at the same time, and to have EU-wide CCS deployment and retrofitting by a fixed point in time (2020 or perhaps later). Alternatively, public resources may be committed towards CCS operations, either as investment support or through a system of feed-in subsidies, The EC legislative framework on State Aid would need to be adjusted to allow Member States to financially support CCS operations. Furthermore, a low-carbon portfolio standard may be introduced for electricity generators to ensure a minimum share of CCS in the EU electricity generation mix. We will discuss the strengths and weaknesses of each of these instruments. They can also be characterised in a number of ways, including their effectiveness in stimulating CCS, and the incentive to further improve the technology and reduce costs. In addition, policies may interact with the EUETS and compete with available public resources for renewable energy; an issue that is often brought up as a downside of CCS (e.g., van Alphen et al., 2007). We will run through a number of criteria in Section 4 to explore these characteristics. The method of criteria analysis and the criteria themselves are based on the Impact Assessment Guidelines of the European Commission.

\section{Characterisation of policy instruments for stimulating CCS}

This section discusses the main features of various policy options, at the EU and the Member State level that could be considered to advance CCS. We will start with the EU-ETS. An obligation for capturing and storing $\mathrm{CO}_{2}$ is also considered a serious option, at least for new coal-fired power plants, but possibly also for existing plants and/or gas-based capacity. ${ }^{2}$ Another possible EU-wide instrument would be a low-carbon portfolio standard. In addition, on the Member State level, variants of subsidy schemes could prove effective.

\subsection{The EU-ETS}

There are two aspects to regulatory issues related to CCS in the EU-ETS. Firstly, the ETS is an mechanism that should provide an incentive to CCS deployment. In Section 1, we discussed the limitations of market instruments for inducing technological change. Apart from that general point, CCS faces specific barriers related to costs and revenues. Current $\mathrm{CO}_{2}$ market prices as well as future projections for the 2008-2012 period of the ETS show price levels around $21 € / \mathrm{tCO}_{2}$ (Sijm et al., 2005; PointCarbon, 2007). Such prices are likely insufficient for inducing structural deployment of CCS, although they will be

\footnotetext{
${ }^{2}$ COM (2006) 843 final, Communication on Sustainable Power Generation from Fossil Fuels.
} 
high enough for some CCS options (IPCC, 2005). Lower emission ceilings and higher $\mathrm{CO}_{2}$ prices would increase the likelihood of large-scale deployment of CCS, if coupled with long-term (e.g., to 2050) signals and policy commitments on emission reduction targets.

While the ETS has its limitation as a policy instrument to induce technological change, inclusion of CCS in the ETS is considered a precondition for large-scale deployment. The second aspect of including CCS in the ETS therefore relates to the formal approval of inclusion of CCS operations. As the result of a recently completed study, the European Commission has indicated its preference to allow CCS as an opt-in installation under Article 24 of the ETS Directive from 2008 onwards. ${ }^{3,4}$ Such an approval should include due safety checks to ensure that all components in the CCS chain appropriately avoid emission of $\mathrm{CO}_{2}$. For the second phase of the ETS, combustion, capture, transport, and storage installations would be opted in as a single installation. Up to 2012, the separate elements of any CCS chain would most likely have to be located within a single Member State. European Union Allowances (EUAs) for these chains would have been allocated to the combustion installation in the National Allocation Plans (NAPs) for the second budget period.

Obviously, this approach has certain limitations. It may complicate transboundary CCS operations, and could in the future give rise to the question by which NAP such operations would need to be covered. It may also provide organisational barriers to CCS implementation, as power-sector and storagesector companies would have to cooperate in a joint venture.

The third phase of the ETS, from 2013 onwards, provides a policy window to pursue a number of modifications to the treatment of CCS under the ETS. Here, we discuss two possibilities. Firstly, capture, transport and storage operations could be opted in as distinct installations under the ETS. This will clearly allocate risks and liability for emissions to operators of the distinct elements in the CCS chain, and better accommodate CCS configuration with multiple operators.

The second major possibility is to consider source and capture plant as one single installation in Annex I of the Directive. The current practice, whereby no allowance is given for transport and storage, could be continued, in which case commercial arrangements would need to be made between combustion and capture installations, on the one hand, and

\footnotetext{
${ }^{3}$ An alternative approach might be not to define CCS operations as a distinct activity. In that case, $\mathrm{CO}_{2}$ capture would be considered as an investment in $\mathrm{CO}_{2}$ abatement technology, undertaken by installations incumbent in the ETS. While in principle this route could result in the same environmental and economic outcome, it lacks an important legal indemnity. Article 24(1) specifies that new activities may participate in the EU-ETS 'taking into account all relevant criteria, in particular effects on the internal market, potential distortions of competition, the environmental integrity of the scheme and reliability of the planned monitoring and reporting system'. This provision should provide additional assurance that the uncertainties related to the risks of CCS and its inclusion in the ETS are addressed properly.

${ }^{4}$ Another example of an opt-in activity under Article 24 is the inclusion of $\mathrm{N}_{2} \mathrm{O}$ from the production of nitric acid, as foreseen in the French and Dutch NAPs for the second budget period.
}

transport and storage installations, on the other, so as to compensate the latter adequately for their efforts. Monitoring and reporting guidelines for transport and storage would be implemented in the normal way (see for a detailed elaboration Zakkour et al., 2007).

Difficulties in accounting for $\mathrm{CO}_{2}$ in the CCS value chain could relate to the involvement of various Member States jurisdictions in the CCS chain; the potential seepage of fugitive emissions from capture installations and during transport, and potential long-term seepage from geological reservoirs. As for the transboundary transfer of $\mathrm{CO}_{2}$, this issue may be solved by making capture, transport and storage installations eligible as separate ETS activities, as suggested above. The capture installation would be allocated emission allowances and would need to surrender sufficient EUAs to cover its emissions. Seepage during operation would need to be accounted for by the installation to which EUAs were allocated.

Long-term seepage, taking place after site closure and abandonment and therefore after the project has stopped generating allowances, arguably poses the largest challenge to proper accounting of $\mathrm{CO}_{2}$ emission reductions. Although the storage operation may be included as an installation under the ETS in order to require it to surrender allowances for emissions, this would not provide any assurance for longterm seepage from the reservoir, given that the storage reservoir would probably not remain an installation under the ETS in perpetuity. We discuss two ways of dealing with the issue of long-term credit liability:

(a) $\mathrm{CO}_{2}$ credits generated through CCS activities could be discounted according to projections of seepage out of the reservoir in accordance with detected seepage from storage locations. This would affect the value of CCSEUAs in the market negatively, and a separate commodity or type of credits would have to be created alongside common EUAs. To be absolutely fair to good sites as compared to suboptimal sites, the credits would even have to be site-specific. Another intricacy would be the practical uncertainty in determining exactly how much $\mathrm{CO}_{2}$ will escape, and thus the degree by which EUAs should be discounted. There is a compelling case (Zakkour et al., 2005) therefore not to reduce the value of EUAs, but leave them unaffected.

(b) Once the storage operation had met the conditions for liability transfer agreed in agreement with relevant technical standards, the Member State could take over post-closure liability. In this case, seepage would be accounted for in the National Greenhouse Gas Inventories of the countries where the storage operation is located.

Obviously, the difficulties related to transboundary transport or sub-soil migration of $\mathrm{CO}_{2}$ may be circumvented if EUAs were allocated or auctioned under an EU-wide ETS emissions cap.

\subsection{Targeted investment support}

A range of pilot and demonstration projects have been proposed so far in a number of EU Member States (see, e.g., $\mathrm{EC}, 2007)$. Yet capital requirements for capturing $\mathrm{CO}_{2}$ in a power plant are substantial, and, despite the optimistic 
announcements, few investors seem willing to provide the required capital as long as it is uncertain what the returns on such investments would be. Therefore, targeted investment support may be very effective for incentivising CCS demonstrations. As capital costs of capture operations are high (IPCC, 2005), investment subsidies in absolute terms for those operations may well be more significant than financial support for other elements in the CCS chain. It is also conceivable that in some cases governments would want to partly fund investments for the storage operation, by subsidising directly or indirectly via research programmes in the field of monitoring (see, e.g., the SACS project associated with Sleipner, which was subsidised by Norway and the EU), or via a public-private partnership with a government that slowly pulls back from the consortium as investors come in.

\subsection{Feed-in schemes}

Feed-in schemes have become widely used to stimulate the introduction of electricity from renewable sources (IPCC, 2007). In a feed-in scheme, a fixed fee is guaranteed per unit of renewable electricity produced, to compensate for the higher costs of the project vis-à-vis conventional alternatives. The fee is usually dependent on the technology, the fuel used (in the case of CHP subsidies, for instance) and the development stage a particular technology is in.

Two main approaches to feed-in subsidies are feed-in tariffs (FIT) and feed-in premiums (FIP). In a FIT scheme, a fixed amount of money (tariff) is paid for the electricity produced (van Tilburg et al., 2007). A producer who receives a feed-in tariff effectively sells his electricity to the payer of the fee (usually the national government). In a FIP scheme on the other hand, a fixed fee (premium) is paid only to compensate for the financial gap of renewable electricity. With this approach the electricity is sold separately on the regular market. Under both FIP and FIT schemes, fees are usually fixed for a long time, ranging from a few years to indefinitely (i.e., the technical lifetime of the project) to create long-term certainty for investors. A variety of approaches to financing these schemes exist. Costs may be collected through connection-charges, as a mark up in the electricity price like in Germany (FIT) or the scheme may be financed from the national budget like in the Netherlands (FIP).

Feed-in systems have proven very effective in stimulating new investments in renewable generation technologies, as evinced by the fast expansion of wind-power generation in Denmark, Germany, and Spain (REN21, 2006). Feed-in schemes are simple and transparent. Since investors are guaranteed long-term income security, banks are willing to provide loans and allow project-finance constructions. Its proven effectiveness in stimulating near market technologies makes this policy option worth considering for the promotion of largescale CCS in Europe. In the Netherlands, a FIP scheme has been explored for low-carbon electricity (de Coninck et al., 2005), but as yet this option is not considered by the Dutch government.

Despite its wide-spread application and effectiveness, the instrument has a number of weaknesses. For instance, it is likely to result in overshooting or undershooting any target that may have been set for low-carbon electricity (van Tilburg et al., 2007). This is because normally no maximum or minimum level is set for the amount of low-carbon electricity compensated, and the output of such electricity is merely driven by the total amount the electricity producers wish to supply. It seems unlikely however that this would be a problem for the target of 10-12 CCS demonstrations in the EU. Lastly, a feed-in subsidy does not lead to incentives for reducing consumption of electricity because the consumer price of electricity does not rise.

\subsection{Guaranteed $\mathrm{CO}_{2}$ price for $\mathrm{CCS}$}

While prices for $\mathrm{CO}_{2}$ on the emissions trading market are too low to stimulate construction of new CCS capacity, policymakers may consider funding the gap between the costs of $\mathrm{CO}_{2}$ reduction and the $\mathrm{CO}_{2}$ market price. This is a carbon price analogy to the electricity cost gap subsidy in a FIP scheme. Such an instrument could be introduced for CCS only or for other abatement technologies as well. Governments could warrant buying back EUAs generated by CCS against a fixed price. Thus, uncertainty as to how much of its investment in CCS an industry would be able to recover would be taken away.

$\mathrm{A} \mathrm{CO}_{2}$ price guarantee could be applied to the power sector alone, but it could also be extended to include other sectors that are included in the ETS. This adds extra flexibility to increase scope to the instrument. A number of low-cost capture opportunities and a number of more expensive options in industrial, non-electricity sectors might benefit from such a price guarantee.

The market price for $\mathrm{CO}_{2}$ would affect the choice for specific sector(s) to be targeted by a future $\mathrm{CO}_{2}$ price guarantee policy, because the costs of $\mathrm{CO}_{2}$ capture differ substantially between industrial installations and zero-emission power plants (ZEPs). In the Netherlands, for instance, costs for capturing and storing $\mathrm{CO}_{2}$ from industrial point sources are between 6 and $11 € / \mathrm{tCO}_{2}$ captured, starting with $4 € / \mathrm{tCO}$ for capture (Hamelinck et al., 2001) and $2 € / \mathrm{tCO}_{2}$ for onshore storage (Hendriks et al., 2003). $\mathrm{A} \mathrm{CO}_{2}$ price gap policy would only include industrial point sources if the $\mathrm{CO}_{2}$ market price stays low. A rising $\mathrm{CO}_{2}$ market price would automatically cancel the $\mathrm{CO}_{2}$ price guarantee instrument, as the market price would more than cover the costs of CCS, although it may remain necessary for high-cost $\mathrm{CO}_{2}$ capture options, such as sources in the steel and cement sectors. For capture and storage of $\mathrm{CO}_{2}$ from ZEPs, costs start at $20 € / \mathrm{tCO}_{2}$-avoided (IPCC, 2005) and the instrument would therefore remain in place longer than for sectors with a smaller price gap, such as refineries or ammonia plants.

\subsection{Low-carbon portfolio standard with tradable certificates}

A portfolio standard is a requirement for consumers or their retail suppliers (or, alternatively, electricity generators) to source a minimum percentage of their electricity from specific energy sources or fuels. Portfolio systems for renewable electricity have recently been introduced in, among other areas, Australia, Japan, and at least 13 states of the US. The following EU countries have adopted a portfolio system: the UK, Belgium, Italy, Sweden, and Norway, although results 
have varied much and depend on the design of the system. Most countries that have opted for a portfolio standard have chosen a midstream/downstream variant, i.e., they assigned the portfolio compliance obligation to electricity consumer or their suppliers (electricity distribution companies). So far, only Italy has opted for an upstream portfolio system, imposing the obligation on power generators and importers (Linden et al., 2005).

A portfolio standard could be set up in a way to include electricity from installations where $\mathrm{CO}_{2}$ is captured and stored as well. In order to provide flexibility to participants with a portfolio obligation and to reduce their compliance costs, a parallel system of tradable certificates can be introduced to certify eligible electricity, similar to current proposals of systems of tradable permits for renewable electricity. Any company generating low-carbon electricity by capturing $\mathrm{CO}_{2}$ would receive CCS certificates. If a company has more permits than it needs, it can sell the surplus to companies that fall short of their target. Such a system can ensure minimum aggregate system compliance costs. Participants in areas with high marginal costs for CCS-based electricity can import their certificates from areas with lower marginal costs.

A portfolio standard is potentially an effective instrument to stimulate the introduction of CCS in the EU. In competitive markets strong incentives are passed on to producers and their equipment suppliers to cut costs and seek cost-reducing innovation. Chief strengths of the system are that environmental targets will be achieved, as long as regulations are well-designed and enforced. If the system is complemented by certificate trading, this ensures that targets are achieved at lowest costs, which as such is appreciated by electricity suppliers. The exact definition of the portfolio standard, in particular the minimum requirements for renewable energy vis-à-vis CCS, will also determine greatly the position of environmental NGOs with respect to this instrument.

\subsection{CCS obligation for new installations after 2020}

The Commission's Communication on Sustainable Fossil Fuels ${ }^{5}$ outlined the possibility of a " $\mathrm{CO}_{2}$-emission phase out", which essentially means the obligation of CCS for all new fossil-fuel-fired power stations from 2020 onwards. This straightforward "command and control" measure contrasts with the market-based approach taken in the ETS. In principle, such an obligation could be expanded to other industries that represent large $\mathrm{CO}_{2}$ point sources. Early candidates would be refineries, ammonia factories, and hydrogen plants. Once the technology is more developed, cement and steel factories can be included. In the long run, also $\mathrm{CO}_{2}$ capture from biomass plants could be considered.

An obligation could be accompanied by smart measures that enable earlier phase-out of existing $\mathrm{CO}_{2}$ emitting coalbased power plants, primarily related to timing of major upgrades or refurbishment. A measure could be included for instance that over the course of 2020-2040, all coal-fired power plants are retrofitted with CCS, which would speed up the phase-out of old-fashioned power plants. This would even be made easier if an obligation that all fossil-fuel-fired power

\footnotetext{
${ }^{5}$ COM (2006) 843 final.
}

stations should be built "CCS-ready" from 2012 onwards would be included, although this can also be left to the operators if the obligation for retrofitting is announced sufficiently ahead of time. In such a way, by 2040 , all $\mathrm{CO}_{2}$ emitting coal-fired power plants could be retrofitted with CCS.

CCS mandate is a rather drastic instrument, and might lead to resistance among Member States with a high dependence on fossil fuels but a low potential for $\mathrm{CO}_{2}$ storage. Contrary to a subsidy or an portfolio standard system, it is a discrete policy instrument-it is either on or off, and its stringency cannot be varied gradually. It is not practical to oblige only half of fossilfuel-fired power production to apply CCS.

On the upside, the instrument is unlikely to lead to a lot of resistance amongst environmental NGOs, since an obligation would not take away financial resources from other energyrelated mitigation options. Also, the mandate encourages investments in more efficient $\mathrm{CO}_{2}$ capture technologies, and, at the time of construction, state-of-the-art technologies will be applied, allowing for further improvements and innovation. A condition for this would be that the mandate should not be restricted to known $\mathrm{CO}_{2}$ capture technologies, so as not to exclude any possibilities, but should pose a generic mandate, e.g., to capture and store at least $85 \%$ of the greenhouse gases that would be emitted in the case a conventional plant was built.

\section{CCS in a level-playing field?}

Before weighing the different policy options to provide incentives for CCS that were introduced in Section 2, it is insightful to discuss CCS in the context of the existing climate and energy policy landscape.

\subsection{Interaction with the EU-ETS}

The impact of any instrument that tilts the mix of mitigation options towards CCS on an emissions trading market will lead to greater deployment of a relatively expensive abatement technology (although it may lead to longer-term increases in efficiency through correction of the innovation market failure).

Introducing a technology bias in an emissions trading scheme, through regulation or subsidy, has a depressing effect on the price of EUAs. This is illustrated in Fig. 1. Fig. 1a shows the marginal abatement cost curve before an additional policy on CCS is introduced. Suppose the emission reductions enacted by the ETS are $50 \mathrm{MtCO}_{2}$ /year, this would lead to an equilibrium carbon price of $p_{\mathrm{e}}$. The $10 \mathrm{MtCO}_{2} /$ year of CCS options, with mitigation costs of $p_{\text {ccs }}$, are more expensive than the $p_{\mathrm{e}}$, so CCS will not be realised.

Fig. $1 \mathrm{~b}$ shows what happens when flanking policy is introduced that induces the implementation of the $10 \mathrm{MtCO}_{2} /$ year of CCS. In case the allocation of allowances remains unchanged, the abatement apart from CCS will decrease to $40 \mathrm{MtCO}_{2}$ /year, thus depressing the carbon price.

Thus, any flanking CCS policy will decrease EUA price levels. This applies for all additional instruments, be it an investments subsidy, a guaranteed $\mathrm{CO}_{2}$ price, a portfolio standard or an obligation. 

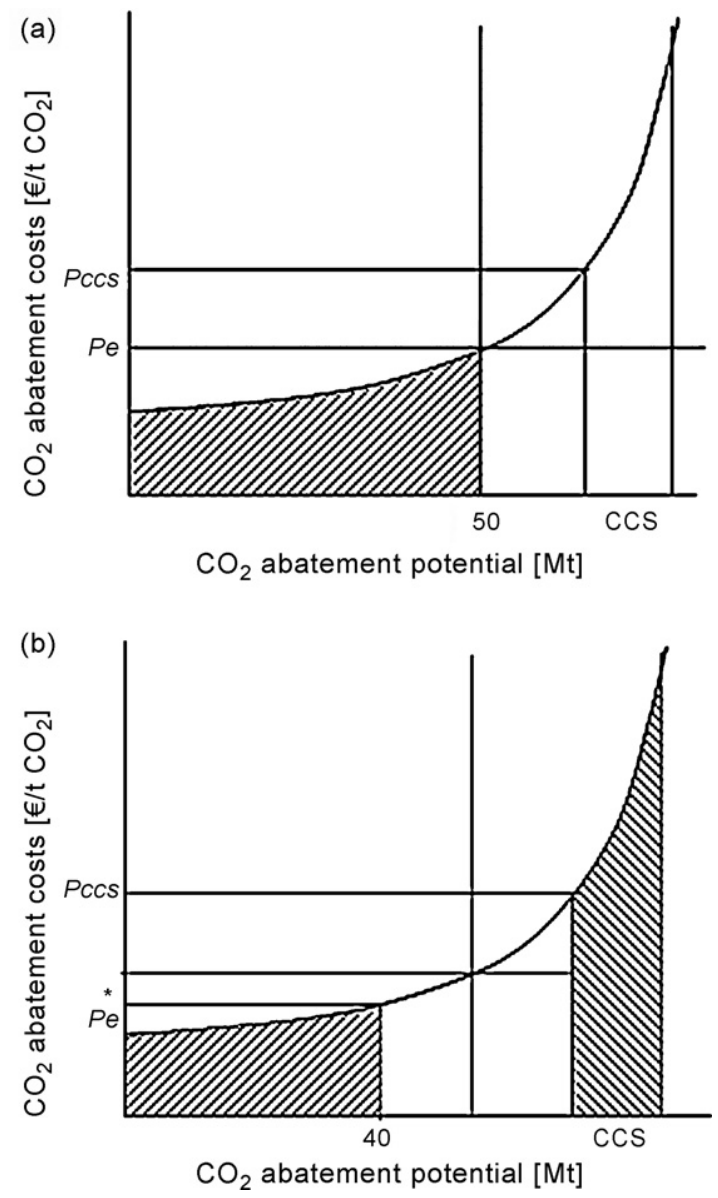

Fig. 1 - Marginal abatement costs curves for a portfolio of $\mathrm{CO}_{2}$ abatement options (a) excluding and (b) including $\mathrm{CCS}$ technologies.

There is a variety of ways to address this market impact. The most straightforward way is to adjust the overall allocation based on the expected realisation of CCS as a consequence of the flanking policy. I.e., if an obligation is expected to lead to $2 \mathrm{MtCO}_{2}$ /year fewer emissions in Germany, Germany's allocated allowances should be cut by $2 \mathrm{MtCO}_{2} /$ year. In the case of fully auctioned allowances, the number of allowances auctioned should be reduced with the expected implementation of CCS as a consequence of the flanking policies. The impact on the carbon price can thus be countered through the overall level of EUAs grandfathered or auctioned.

In general, instruments that are likely to be implemented at the EU level, such as a CCS mandate or a low-carbon portfolio will have a wider geographical scope. Therefore, they may well have a greater reducing impact on $\mathrm{CO}_{2}$ credit prices than (financial) instruments at the Member State level.

\subsection{Incentive for cost reduction}

The impact of the incentivising policies on ongoing cost reductions will differ. A low-carbon portfolio standard and an obligation will provide incentives for CCS without spending a significant share of the government budget on subsidies. These instruments will pose the costs and risks related to CCS on the CCS operator, which is likely to advance innovation in particular in $\mathrm{CO}_{2}$ capture technology. This higher cost burden on the operators does not need to unduly distort the internal electricity market, if the same obligation applies to all operations. An obligation for a certain technology, especially one which has not been demonstrated on a full scale yet, poses to the operators a risk of a failing technology. Although the concept of CCS is certainly proven, the practicalities of scalingup capture in power sector are by no means all solved. In addition, lack of sufficient storage reservoirs in areas with rising electricity demand may lead to disproportionally high costs for various regions in the EU.

In general, further technological development and cost reduction is likely to be discouraged if part or all of the costs of CCS are covered by public funds. This is true for investment support, a feed-in system, and a $\mathrm{CO}_{2}$ price guarantee alike. The remaining incentive for further innovation under such instruments will depend on the level of support provided. These instruments will place part of the risk with governments. This is a disadvantage in particular since governments do not control costs but will depend on cost information from the operators. There might even be a risk of collusion of pricing to the extent that operators would work together to provide single estimates of the costs of CCS, rather than submitting information on costs in individual operations.

In addition, these financial instruments put a substantial burden on the government budget, and it is likely that they would be implemented at the Member State rather than at the EU level. Required capital in new electricity generation capacity with current capture technologies is substantial. Incremental capital required for capture capacity on top of costs for construction of the combustion plant is $515-725 €_{2005} / \mathrm{kW}$, for new pulverized coal plants this would be $1160-1490 €_{2005} / \mathrm{kW}$, and for IGCCs $1170-1570 €_{2005} / \mathrm{kW}$ (based on Chapter 3 in IPCC, 2005). Depending on its scale, capital support to CCS projects could in the time span up to 2015 contribute to the realisation of up to 12 demonstration projects for sustainable fossil fuels aspired by the Commission. Potentially there will be a continued demand for investment support after 2015 to further industrial-scale deployment of CCS.

Costs for a feed-in system may also be very high if the system is successful and leads to much deployment of CCS. Ultimately, the taxpayer instead of the electricity user would cover the full extra costs of low-carbon electricity. Downward adjustment of the tariffs or premiums, because learning brings down the costs and the compensation of the financial gap can be reduced, may meet resistance among producers.

Key to the total cost of a $\mathrm{CO}_{2}$ price gap policy will be the market price for $\mathrm{CO}_{2}$, which is uncertain. For the 2008-2012 period projections are between 10 and $25 € / \mathrm{tCO}_{2}$ (Sijm et al., 2005; PointCarbon, 2007) $)^{6}$ depending on the National Allocation

\footnotetext{
${ }^{6}$ Over the period January-July 2005, the market price for $\mathrm{CO}_{2}$ was between 6 and $30 € / \mathrm{tCO}_{2}$. Prices have increased during 2005, dropped by the end of 2005 , rose again up to $30 € / \mathrm{tCO}_{2}$ and then plummeted down to $10 € / \mathrm{tCO}_{2}$. Prices were stable at around $15 € /$ $\mathrm{tCO}_{2}$ from May 2006 onwards, until in January 2007, prices went down again to around $5 € / \mathrm{tCO}_{2}$. PointCarbon (2007), in a recent report including the most recently submitted and corrected NAPs, arrive at a carbon price of $21 € / \mathrm{tCO}_{2}$ over the 2008-2012 period.
} 
Plans, but also on external conditions such as weather and economic growth. Energy prices have a major influence as well. Higher oil and gas prices have resulted in a higher gas-to-coal price ratio, and as a consequence have favoured coal-based electricity, which is more carbon-intensive and generates demand for $\mathrm{CO}_{2}$ credits. If this trend continues, it would exert an upward pressure on the $\mathrm{CO}_{2}$ market price. Alternatively, an eventual drop in oil and gas prices would lead to a lower $\mathrm{CO}_{2}$ market price. Trading of possibly cheaper credits from JI and CDM projects on the European carbon market will also bring down the price of $\mathrm{CO}_{2}$ credits.

\subsection{Competition with renewable energy}

It is an often-raised concern that Member States divert resources away from renewable energy, thus lowering the likelihood of complying with their renewable energy targets. Diversion of funds can happen on the level of R\&D, where it would be relatively easy to demonstrate, but also in terms of political media, industry and public attention. It might even be possible that a renewable energy portfolio standard is replaced by a low-carbon portfolio standard, or that commercialisation subsidy for renewables will include CCS. In those cases, the resources will clearly be divided over renewable energy and CCS, rather than only falling to renewable energy, and diversion of resources would take place.

It is unsure whether such interactions will raise concerns if they are limited in scope to R\&D budgets. However, in the case of clear policy diversion, it is likely that environmental organisations as well as the renewable energy lobby will resist. It might be possible to reduce the negative impact of the inclusion of CCS in the mitigation portfolio on renewable energy implementation by making the share of renewables in research and development funding, as well as in a portfolio standard, dependent on the amount of CCS implemented. For instance, if $15 \%$ of all electricity would have to be low-carbon because of a CCS portfolio standard, one could at the same time adopt a resolution that the share of renewable electricity has to be twice as high.

\section{Multi-criteria analysis of options}

After having evaluated some of the relevant issues of CCS in the EU policy playing field, we discuss the various policy options by means of a criteria-analysis. We distinguish four relevant criteria related to environment, economics, policy embedding and public acceptance:

1. Effectiveness. The extent to which options can be expected to achieve the objectives of the flanking policy.

2. Cost burden. The extent to which financial risk of CCS projects is born by those who are informed best on the costs: the CCS operators.

3. Interaction with the EU-ETS. The extent to which options are likely to reduce the price of $\mathrm{CO}_{2}$ allowances.

4. Competition with renewable energy. The extent to which the option may divert public funds from renewable energy sources. The assessment of this criterion focuses on concerns of the NGO community.

As all criteria analyses, this analysis has its limitations in terms of refinement of the criteria, and scope and detail of policy options. For instance, one might consider further detailing policy options to include subgroups with a smaller scope of application, so an instrument such as an EU-wide CCS obligation can be better compared to the case when only one or two Member States would implement investment subsidies on CCS. Nevertheless, we feel that these four criteria capture the most essential issues around incentivation of CCS.

The results of the multi-criteria analysis are summarised in Table 1.

Effectiveness of the EU-ETS depends largely on the $\mathrm{CO}_{2}$ market price. If CCS were to be enabled under the EU-ETS, CCS would be gradually picked up by the market at a $\mathrm{CO}_{2}$-price of $€ 40 / \mathrm{tCO}_{2}$ in 2020 , increasing to around $€ 45$ in 2030 . This would be enough for some (coal-based) CCS to be deployed by the market (EC, 2008d). To underline the importance of the $\mathrm{CO}_{2}$ market price for the effectiveness of the EU-ETS, we distinguish here between a "weak" ETS scenario with a price signal of around $20-30 € / \mathrm{tCO}_{2}$ in 2030 , which would have a negative result for CCS deployment, and a "strong" ETS, which could yield EUA prices of around $70 € / \mathrm{tCO}_{2}$, supposedly enough to incentivise structural deployment of large-scale CCS. The dynamic efficiency of the scheme - i.e., the extent to which innovation and technological change is stimulated - is not guaranteed in both cases. The other instruments are all designed to increase that effectiveness for the case of CCS.

Scores on the "cost burden" criterion vary across the policy options. In general, the policies that provide subsidies pose a
Table 1 - Multi-criteria analysis of policy options Options

\section{Criteria}

Interaction ETS

Competition renewables

CCS in ETS (weak incentive)

CCS in ETS (strong incentive)

Investment support

Feed-in subsidies

$\mathrm{CO}_{2}$ price guarantee

Low-carbon portfolio standard

CCS obligation

Effectiveness

Cost burden

the

$\begin{array}{ll}- & + \\ + & + \\ + & + \\ + & + \\ + & + \\ + & + \\ +++ & \end{array}$

+, Positive result on criterion; -, negative result on criterion; 0, positive nor negative result on criterion (indifferent); +/0/-, result on criterion depends on details of implementation (e.g., on allocation in ETS). 
Table 2 - Mechanisms leading to lower production costs with increased adoption (based on Sandén and Azar, 2005)

Economies of scale in production

Learning by doing

Incremental product development

Economies of scope-complementary resources and production processes
Production costs per unit of output decrease when fixed costs are spread over an increasing production volume. Increased production volumes also enable increased division of labour

Production processes and organisation are refined and the skill of workers increases with cumulative production

Learning by doing and learning by using can feed back into incremental product development. The product is refined to increase the performance-to-cost ratio and better meet the needs of users and producers

The growth of one technology may induce a use of by-products. The value of the by-product can lower the net cost to produce the initial main product. The multiple outputs of oil refineries may serve as example higher risk and cost burden on government. We have assessed this as negative for two general reasons: information asymmetry, which decreases cost effectiveness of policies, and incentives for cost reduction. If the level of subsidy is determined by a government, which is the case for investment subsidies, $\mathrm{CO}_{2}$ price guarantees or feed-in subsidies, it is likely that the government will pay more than strictly necessary to cover the incremental CCS costs, because the level of information of governments is lower than the information that the CCS operators have. This information asymmetry may then decrease the cost effectiveness of the policy. In the case of the obligation for CCS or a low-carbon portfolio standard, the cost and risks will be placed on the CCS operators. Not only will this be good for cost-effectiveness as not more funding will be placed on CCS than necessary, also the CCS operators will have an incentive to improve CCS technology in order to keep the costs low.

As for interaction with the ETS, all options will intermingle with the trading scheme, and may depress EUA prices. However, this can be corrected if the overall (or MS-specific) number of allocated allowances is corrected for the market distortion. The EU level policies will likely have a greater scope and would therefore have a larger impact on the ETS than the policies of single Member States. In addition, the difficulty in correcting the cap to minimise the ETS efficiency effects will be different at the Member State level than for the EU level.

The "impact on renewables" criterion is particularly important for the position of environmental organisations - who are likely to influence public perception of CCS. It can be argued that on the EU level, obligation and portfolio instruments can be linked to renewables implementation levels. On the MS level, where a range of greenhouse gas abatement technologies compete for limited funds, this problem will be more severe. It should be noted that the views of the environmental NGO community are represented here. For the business sector, the feasibility would probably be higher for the MS policies and lower for an EU-wide obligation. Note that low CCS deployment levels following a weak price signal may be welcomed by some, in particular environmental NGOs who fear that CCS will lead to a lock-in in a fossil fuel-based energy supply. Views from NGOs on an ETS with strong price signal may well diverge: on the one hand such a scheme would advance such a lock-in, on the other hand it would help to curb $\mathrm{CO}_{2}$ emission considerably on the short to medium term.

\section{Timing of CCS policy options}

While the policy options evaluated each have their own strengths and weaknesses, they may well complement each other as the technology matures. Sandén and Azar (2005) have provided a useful framework to match technical maturity with policy instruments. They distinguish three phases of maturity, ${ }^{7}$ each of which requires it particular incentivising policies.

In the demonstration phase, incentives are needed to bring down production costs while increasing adoption (Table 2). Of course, costs related to plant design, steel, chemicals $/ \mathrm{O}_{2}$, and financing will remain. Bringing down costs of immature technologies will often involve the provision of the capital required to realise demonstrations. For CCS, this phase will comprise the construction of up to 12 demonstration plants.

In the up-scaling phase, the technology will have gained a certain momentum, and other incentives will be needed to induce more users and investors to take on the technology. At this stage, the costs of the technology are sufficiently low, but incentives are needed to advance the diffusion of the technology. Such incentives should help triggering mechanisms that will increase attractiveness of a technology (Table 3). In this phase, policies must advance wide-spread awareness of the option and reduce the financial risks associated with the deployment of a technology. An obligation of the technology may accelerate the rate of up-scaling. This phase will entail the construction of a 'second generation' of CCS plants over a 10-15 year period.

In the commercial phase, the technology can be considered mature. It will be one of a range of cost-competitive options to abate emissions. In this phase, economy-wide price instruments should provide sufficient incentive to induce deployment of the technology. An obligation of the technology may be also considered. In this phase, CCS should be one of the lowest cost options for carbon dioxide reduction, and should be able to exist unsupported by additional policies. This phase may start at any moment between 2025 and 2040, depending on the rate of diffusion of the technology.

Each of the instruments discussed above has its own characteristics and may be deployed in one or various innovation phases.

Investment subsidies could be used to incentivise CCS in various stages of technological maturity, but is most likely to be for large-scale demonstration of the technology.

\footnotetext{
7 Note that the IPCC uses a different qualification of maturity.
} 
Table 3 - Mechanisms making a technology more attractive for users and investors with increased adoption, regardless of price (based on Sandén and Azar, 2005)

Decreasing uncertainty

The adoption of a technology will decrease the uncertainty of its merits. Risk adverse producers, users and investors prefer a better-known technology. This is probably of extra importance when it comes to consumer goods, such as private cars and domestic heating systems

Learning by using The performance of a technology increases and service costs decrease when users gain experience, in particular valid for complex capital goods such as aircraft and power plants, but also maintenance of consumer capital goods such as cars and houses

Economies of scale in consumption-user networks The benefit that a consumer derives from using a good sometimes depends on the number of other consumer purchasing compatible items. For example, if many use the same standard, the cost of complementary goods will decrease and their availability will increase. The availability of machine service and spare parts will also increase

Feed-in subsidies are unlikely to be used for CCS while it is still in the demonstration phase, given the technological uncertainties that still surround an option in that phase. Feedin schemes are suitable to reduce the financial risks from CCS operations technologies, and may thus be deployed in the upscaling and the commercialisation phase. There is an important risk, however, that further innovation in CCS technologies, and further cost reduction, would be halted by a feed-in subsidy, which may be particularly problematic in the up-scaling phase.

Likewise, a $\mathrm{CO}_{2}$ price guarantee is not particularly suitable to provide the substantial capital needed for realising largescale demonstrations. It may, however, be a useful instrument for stimulating CCS in the up-scaling phase, whilst CCS does not provide a cost-competitive opportunity to reduce $\mathrm{CO}_{2}$. Under these circumstances, it will help to reduce the financial risk for investors in CCS technologies. If the instrument would apply to CCS only, it would help to enlarge the share of CCSbased emissions reductions in the mitigation portfolio. However, a $\mathrm{CO}_{2}$ price guarantee would also involve the risk of disincentivising ongoing innovation of CCS technologies. Once CCS technologies have matured, maintaining a subsidy in the form of $\mathrm{aCO}_{2}$ price guarantee no longer seems justified.

Including CCS in a low-carbon portfolio standard may be considered once CCS is beyond the demonstration phase. A portfolio standard will contribute to diffusion of the technology and as such seems an appropriate instrument to use in the up-scaling phase. In the commercial phase, a portfolio standard may be made more stringent to reflect the maturity of CCS technologies.

CCS technologies will need to have matured to some extent before an obligation can be considered. An obligation can be applied to an option still in the demonstration phase, but would need to take effect at some date in the far future, e.g., 10 years. In that way, companies have time to prepare themselves. A mandate may be considered in the demonstration phase to accelerate diffusion of the option, or in the commercial phase, when the technology will be widely accepted.

Table 4 attempts to structurally evaluate how combinations of policies could provide the most effective incentive to further deployment of CCS technologies.

\section{Conclusion}

This paper has reviewed, discussed and evaluated weighted a number of policy options to incentivise CCS. The question how CCS may be structurally deployed is particularly relevant in the context of the legally binding emission reduction targets that the EU has set itself. Without CCS, these targets would be difficult to meet, and more expensive than otherwise.

Although the EU-ETS is the most cost-effective instrument to reduce greenhouse gas emissions, there are substantial questions as to whether its weak scenario will lead to sufficient deployment of CCS in the short term because of low incentive levels, short-trading periods, and the "innovation market failure". If a strong ETS scenario would be politically unfeasible, additional instruments on the EU and the Member State level can be effective in correcting this failure.

While Member State policies are likely to have less interaction with the ETS and will be more consistent with other policies, they are less attractive from the perspective of environmental organisations as they are more likely to displace resources for other mitigation options and would spend public money on CCS. In addition, these policies tend to pose an important part of the financial risk of CCS projects

Table 4 - Possible timing of incentivising policies for CCS technologies in three innovation phases

\begin{tabular}{lccc} 
Projected time horizon & $\begin{array}{c}\text { Demonstration } \\
\text { 2010-2020 }\end{array}$ & Up-scaling & Commercialisation \\
2015-2030 & 2040 $\rightarrow$ & Yes \\
CCS in ETS (weak incentive) & Yes & Yes & Yes \\
CCS in ETS (strong incentive) & Yes & Yes & No \\
Investment subsidy & Yes & Yes & No \\
Feed-in subsidy & Yes & Yes & No \\
$\mathrm{CO}_{2}$ price guarantee & Yes & Yes & Yes \\
Portfolio standard + certificates & No & Yes & Yes \\
CCS obligation & No & & \\
\hline
\end{tabular}


with national governments, which have only limited insight in the actual costs and risks of CCS. Overall, it seems that EUwide structural policies score higher on the identified criteria.

Financial support at the Member State level may be particularly advantageous for realising CCS demonstrations and to advance up-scaling. In the absence of a stronger carbon price signal, an EU-wide low-carbon portfolio standard or CCS mandate will be needed ensure wide spread deployment of CCS in the long run. Such a mandate is also likely to speed up the availability of CCS in the portfolio of mitigation options, and may therefore increase the overall cost-effectiveness of the EU climate policy. However, it is also a rather intrusive measure for such a specific technology, and it would be disadvantageous to countries with limited storage possibilities. EU and Member State policies can be made to complement each other over time to ultimately achieve wide spread introduction of $\mathrm{CO}_{2}$ capture and storage, but the policy framework should allow for coordination to design the most effective and acceptable combination.

\section{Acknowledgements}

Work for this article was carried out within the framework of a project commissioned by DG Environment of the European Commission. This project aimed to provide technical support to the EC to elaborate an enabling policy framework for CCS by the end of 2007. The authors are very grateful to Jos Sijm, Christian Hudson, Paul Zakkour and Scott Brockett, who provided worthwhile comments to earlier drafts, and to Xander van Tilburg, for his valuable input.

\section{REFEREN CES}

de Coninck, H.C., Dijkstra, J.W., Jansen, D., Lako, P., 2005. Klimaatneutrale elektriciteit en de MEP. ECN-C-05-033. Energy Research Centre of the Netherlands, Petten/ Amsterdam.

de Coninck, H., Anderson, J., Curnow, P., Flach, T., Groenenberg, H., Norton, C., Reiner, D., Shackley, S., Sigurthorsson, G., 2007. Is CCS ready to roll? Reflections on social, economic, and regulatory requirements. J. Eur. Environ. Law Policy 5, 412-424.

DNV, Anderson, J., de Coninck, H., Curnow, P., Flach, T., Reiner, D., Richardson, P., Shackley, S., Upham, P., Sigurthorsson, G., 2007. The ACCSEPT Project: Multidisciplinary Analysis and Gap-filling Strategies. Available on www.accsept.org.

EC, 2007. Communication from the Commission to the Council and the European Parliament: sustainable power generation from fossil fuels: aiming for near-zero emissions from coal after 2020. COM (2006) 843 Final. January 10, 2007, Brussels.

EC, 2008a. Proposal for a Directive of the European Parliament and of the Council on the geological storage of carbon dioxide. COM (2008) 18 Final. January 23, 2008, Brussels.

EC, 2008b. Communication from the Commission to the European Parliament, the Council, the European Economic and Social Committee and the Committee of the Regions. Supporting early demonstration of sustainable power generations from fossil fuels. COM (2008) 30 Final. January 23, 2008, Brussels.
EC, 2008c. Proposal for a Directive of the European Parliament and of the Council amending Directive 2003/87/EC so as to improve and extend the greenhouse gas emission allowance trading system of the Community. COM (2008) 30 Final. January 23, 2008, Brussels.

EC, 2008d. Commission staff working document accompanying document to the Proposal for a Directive of the European Parliament and of the Council on the geological storage of carbon dioxide. Impact assessment. COM (2008) X Final. January 23, 2008, Brussels.

European Council, 2007. Presidency Conclusions. 7224/1/07 REV1 CONCL1. March 8-9, 2007, Brussels.

Geels, F.W., Elzen, B., Green, K., 2004. General introduction: system innovation and transitions to sustainability. In: Elzen, B., Ges, F.W., Green, K. (Eds.), System Innovation and the Transition to Sustainability. Theory, Evidence and Policy. Edward Elgar, Cheltenham.

Hamelinck, N.C., Faaij, A.P.C., et al., 2001. Potential for $\mathrm{CO}_{2}$ sequestration and enhanced coalbed methane production in the Netherlands. Novem, Utrecht, ISBN: 90-5847-020-4.

Hendriks, C., Wildenborg, T., Feron, P., Graus, W., Brandsma, R., 2003. EC-CASE. Carbon dioxide Sequestration. M70066, December 2003, Ecofys/TNO, Utrecht.

IPCC, 2005. IPCC special report on carbon dioxide capture and storage. In: Metz, B., Davidson, O., de Coninck, H.C., Loos, M., Meyer, L.A. (Eds.), Prepared by Working Group III of the Intergovernmental Panel on Climate Change. Cambridge University Press, Cambridge, United Kingdom and New York, NY, USA, $442 \mathrm{pp}$.

IPCC, 2007. Climate change 2007: mitigation. In: Metz, B., Davidson, O.R., Bosch, P.R., Dave, R., Meyer, L.A. (Eds.), Contribution of Working Group III to the Fourth Assessment Report of the Intergovernmental Panel on Climate Change, Cambridge University Press, Cambridge, United Kingdom and New York, NY, USA, 851 pp.

Jaffe, A.B., Stavins, R.N., 1994. The energy-efficiency gap: what does it mean. Energy Policy 22 (10), 804-810.

Jaffe, A.B., Newell, R.G., Stavins, R.N., 2005. A tale of two market failures-technology and environmental policy. Ecol. Econ. 54, 164-174.

Kemp, R., 2000. Technology and environmental policy: innovation effects of past policies and suggestions for improvement. OECD Proceedings Innovation and the Environment. OECD, Paris, pp. 35-61.

Linden, N.H. van der, Uyterlinde, M.A., Vrolijk, C., Ericsson, K., Khan, J., Nilsson, L.J., Astrand, K., Wiser, R., 2005. Review of International Experience with Renewable Energy Obligation Support Mechanisms. ECN-C-05-025. Energy Research Centre of the Netherlands, Petten/Amsterdam.

OECD/IEA, 2003. Technology Innovation, Development and Diffusion. COM/EVN/EPOC/IEA/SLT(2003)4. OECD Environment Directorate and International Energy Agency, Paris.

PointCarbon, 2007. Analysis of the $\mathrm{CO}_{2}$-price in the Period 20082012. Summary viewed online: http:// www.pointcarbon.com/Home/News/All\%20news/ EU\%20ETS/article20743-467.html.

REN21, 2006. Renewable Energy Global Status Report 2006. Paris. Sandén, B.A., Azar, C., 2005. Near-term technology policies for long-term climate targets-economy wide versus technology specific approaches. Energy Policy 33, 15571576.

Sartorius, C., Zundel, S., 2005. Time Strategies, Innovation and Environmental Policy. Edward Elgar, Cheltenham.

Sijm, J.P.M., Bakker, S.J.A., Chen, Y., Harmsen, H.W., Lise, W., 2005. $\mathrm{CO}_{2}$ Price Dynamics: The Implications of EU Emissions Trading for the Price of Electricity. ECN-C-05-081. Energy Research Centre of the Netherlands (ECN), Petten/ Amsterdam. 
Sorrell, S., Sijm, J., 2003. Carbon trading in the policy mix. Oxford Rev. Econ. Policy 19 (3), 420-437.

Sutherland, R.J., 2000. 'No-cost' efforts to reduce carbon emissions in the US: an economic perspective. Energy J. 21 (3), 89-112.

Suurs, R.A.A., Hekkert, M.P., 2005. Naar een methode voor het evalueren van transitietrajecten. In: Functies van innovatiesystemen toegepast op biobrandstoffen in Nederland, Copernicus Institute, Utrecht University.

van Alphen, K., van Voorst tot Voorst, Q., Hekkert, M.P., Smits, R.E.H.M., 2007. Societal acceptance of carbon capture and storage technologies. Energy Policy 35 (8), 4368-4380.

van den Bergh, J.C.M., Faber, A., Idenburg, A.M., Oosterhuis, F.H., 2007. Evolutionary economics and environmental policy. In: Survival of the Greenest, Edward Elgar, Cheltenham.

van Tilburg, X., Jansen, J.C., Uyterlinde, M.A., Lensink, S.M., 2007. Verplichting voor duurzame elektriciteit in Nederland, Verkenning van mogelijkheden en randvoorwaarden. ECNE-06-38. Energy Research Centre of the Netherlands, Petten/Amsterdam.

Vollebergh, H., 2007. Differential impact of environmental policy instruments on technological change: a review of the empirical literature. Tinbergen Institute Discussion Paper. TI 2007-042/3.

Watson, J., MacKerron, G., Ockwell, D., Wang, T., 2007. Technology and carbon mitigation in developing countries: are cleaner coal technologies a viable option? Human Development Report 2007/2008. Occasional Paper. UNDP.

Zakkour, P., Girardin, C., Solsbery, L., Haefeli, S., Murphy, P., 2005. Developing monitoring, reporting and verification guidelines for $\mathrm{CO}_{2}$ capture and storage under the EU ETS. Department of Trade and Industry Report No. COAL R277 DTI/Pub URN 05/583, January 2005, ERM/DNV.

Zakkour, P., et al. 2007. Task 2: options for alternative modifications to existing legislation. Report by ERM, NortonRose, ECN and CMI for the European Commission.

ZEP, 2006. Strategic Deployment Document. The European Technology Platform for Zero Emission Fossil Fuel Power Plants.

Zundel, S., Erdmann, G., Kemp, R., Nill, J., Sartorius, C., 2005. Conceptual framework. In: Sartorium, Zundel, (Eds.), Time Strategies, Innovation and Environmental Policy. Edward Elgar Publishing, Cheltenham, United Kingdom. 